Acta Theriologica, Suppl. 3: 157-164, 1995.

PL ISSN 0001-7051

\title{
Further studies on the population genetics of the blesbok Damaliscus dorcas phillipsi
}

\author{
Rudolph C. BIGALKE, Günther B. HARTL, Hubertus J. van HENSBERGEN, \\ Savvas VRAHIMIS and Mark P. S. BERRY
}

Bigalke R. C., Hartl G. B., Hensbergen H. J. van, Vrahimis S. and Berry M. P. S. 1995. Further studies on the population genetics of the blesbok Damaliscus dorcas phillipsi. [In: Ecological genetics in mammals II. G. B. Hartl and J. Markowski, eds]. Acta Theriologica, Suppl. 3: 157-164.

For approximately 100 years blesbok - endemic to South Africa - have been extinct in the wild and confined to fenced game reserves or farms. Biochemical-genetic variation was studied in blesbok from five isolated populations using electrophoretic allozyme analysis. Body weights and liver mineral concentrations were also determined. Material was collected from three localities in the Orange Free State province: a large reserve (PRE, ca 10000 ha, $\mathrm{N}=500-600, n=23$ ); a smaller reserve (KOP, ca 3000 ha, $\mathrm{N}=150-200, n=14$ ) with animals derived from the same source; and a farm (MID, ca 4000 ha, $\mathrm{N}=$ up to $700, n=19$ ). The other two localities were a farm in the northern Cape Province (BEN, ca 10000 ha, $N=200, n=18$ ) and another in the southern Cape Province (BRA, ca 150 ha, $\mathrm{N}=50-80, n=27$ ), both with populations derived from small founder stocks. Three loci were polymorphic: Pgm-1, Acy-1, and Gpi-1 but Acy-1 was the only one polymorphic in all five populations. Pgm-1 was polymorphic in two populations derived from the same source and Gpi-1 in the other from the Orange Free State. Calculated over 45 presumptive structural loci the mean proportion of polymorphic loci $(P)$ was $3.5 \%(\mathrm{SD}=1.2 \%)$, and mean expected average heterozygosity $\left(H_{e}\right)$ was $0.9 \%(\mathrm{SD}=0.25 \%)$. The populations separated out by genetic distance in two distinct groups, those from the Cape Province and those from the Orange Free State. There were considerable differences in mean body weight between some sites. No correlation could be detected with level of heterozygosity. Body weight appeared rather to be related to liver mineral levels. In particular the ratio between copper and molybdenium appears important with those animals high in copper and low in molybdenium having a higher body weight.

Department of Nature Conservation, University of Stellenbosch, Stellenbosch 7600, South Africa (RCB, HJvH, SV); Institut für Haustierkunde der Christian-Albrechts-Universität zu Kiel, Olshausenstraße 40, D-24118 Kiel, Germany (GBH); De Beers Consolidated Mines Ltd., P.O. Box 616, Kimberley 8300, South Africa (MPSB).

Key words: Damaliscus dorcas phillipsi, blesbok, population genetics, electrophoresis, genetic variability, trace elements

\section{Introduction}

Population genetic studies of African Bovidae are still scarce and there is no reference system of genetic diversity within and among populations, subspecies and species comparable to that available for Cervidae (Bigalke et al. 1993). The 
present study seeks to contribute to knowledge of biochemical-genetic variation in antelope and to expand on the information derived from a single population of blesbok reported by Bigalke et al. (1993).

The blesbok Damaliscus dorcas phillipsi is endemic to South Africa and was originally present in large numbers on the central plateau grasslands. Its range was settled and converted to farms in the second half of the nineteenth century and it has been confined to fenced farms and reserves for the best part of a century.

Translocations have resulted in an extension of its range beyond the original boundaries (Smithers 1983). It is likely that most farm and reserve populations are derived from small founder stocks. Variation of genetic diversity within and between them is thus of particular interest. The population previously studied by Bigalke et al. (1993) appeared to have lost a grat deal of biochemical-genetic variation and was also characterised by small body size and low levels of copper and zinc. Further studies were indicated to try to separate genetic and environmental effects.

\section{Study area}

Blesbok were collected at five sites. Three localities were situated in the Orange Free State province, the centre of the original range. The other localities lie in the Cape province.

The Willem Pretorius Game Reserve (PRE) is approximately 10000 ha in extent and the blesbok originate from an introduction of 350 animals from the Free State Game Reserve in 1956. Since then the population has been maintained at approximately 550 with a low of 324 in 1977 and a high of 1002 in 1987 (S. Vrahimis, pers. comm.). The Free State Game Reserve (approx. 11000 ha) was proclaimed in 1925 and in 1950 was said to support "several thousandes" of blesbok and springbok (Bigalke 1950), probably from original wild stock. It has since been deproclaimed.

The Koppies Dam Nature Reserve (KOP) is ca 3000 ha in area. When development started in 1956 approximately 18 blesbok were present. These were supplemented by introductions of 18 from Willem Pretorius in 1983 and another 50 in 1989 from Soetdoring NR - which had also obtained its blesbok from Willem Pretorius. Koppies Dam animals are thus largely derived from Willem Pretorius stock. The population was held at about 50 until 1988 and between 150 and 200 since then (S. Vrahimis, pers. comm).

The third locality is a farm Middlekop (MID) of 4000 ha with an old established blesbok population, origin and history unknown, of up to 700 animals.

The other two localities are farms with introduced populations known to be derived from small founder stocks. Benaauwdheidsfontein (Benfontein) in the northern Cape Province (BEN, ca 9400 ha) has about 200 blesbok descended from a small but unknown number of founders introduced from a nearby farm Rooipoort in the 1970's. These animals in turn stem from an introduction of 18 animals, probably from Rietvlei Nature Reserve near Pretoria, Transvaal province, in 1958. Only 5 survived (R. C. Bigalke, pers. obs.).

The remaining population is that from Brakkekuil (BRA, ca 150 ha) in the southern Cape Province, the origin and history of which is described by Bigalke and van Hensbergen (1992). It was introduced in the 1920's from an unknown source and has been maintained at about 60-80.

\section{Material and methods}

Animals were weighted on a spring balance shortly after being shot. Whole carcass mass was recorded to the nearest kilogram and animals were alloted to the age groups adult and subadult on 
body size, coloration and horn characteristics. Liver, kidney and heart samples for genetic studies were frozen immediately after the death of the specimens and stored frozen at $-20^{\circ} \mathrm{C}$ until electrophoresis. Additional liver samples were preserved in formalin. Orange Free State specimens were analysed for trace elements by the regional Veterinary Laboratory at Stellenbosch.

Preparation of tissue extracts, horizontal starch gel electrophoresis and enzyme specific staining procedures were performed according to routine methods (Hartl and Höger 1986, Grillitsch et al. 1992). The following 30 isozyme systems representing a total of 45 presumptive structural loci were screened (abbreviation, E.C. number and loci detected are given in parentheses): $\alpha$-glycerophosphate dehydrogenase (GDC, E.C. 1.1.1.8, $G d c$ ), sorbitol dehydrogenase (SDH, E.C. 1.1.1.14, $S d h$ ), lactate dehydrogenase (LDH, E.C. 1.1.1.27, $L d h-1, L d h-2)$, malate dehydrogenase (MDH, E.C. 1.1.1.37, $M d h-1, M d h-2$ ), malic enzyme (ME, E.C. 1.1.1.40, Me-1, Me-2), isocitrate dehydrogenase (IDH, E.C. 1.1.1.42, Idh-1, Idh-2), 6-phosphogluconate dehydrogenase (PGD, E.C. 1.1.1.44, Pgd), glucose dehydrogenase (GDH, E.C. 1.1.1.47, Gdh), glucose-6-phosphate dehydrogenase (GPD, E.C. 1.1.1.49, Gpd), glutamate dehydrogenase (GLUD, E.C. 1.4.1.3, Glud), catalase (CAT, E.C. 1.11.1.6, Cat), superoxide dismutase (SOD, E.C. 1.15.1.1, Sod-1, Sod-2), purine nucleoside phosphorylase (NP, E.C. 2.4.2.1, $N p$ ), aspartate aminotransferase (AAT, E.C. 2.6.1.1, Aat-1, Aat-2), hexokinase (HK, E.C. 2.7.1.1, Hk-1, $H k$-2), pyruvate kinase (PK, E.C. 2.7.1.40, Pk), creatine kinase (CK, E.C. 2.7.3.2, Ck-1, Ck-2), adenylate kinase (AK, E.C. 2.7.4.3, Ak-1, Ak-2), phosphoglucomutase (PGM, E.C. 2.7.5.1, Pgm-1, $P g m-2$ ), esterases (ES, E.C. 3.1.1.1, Es-d, Es-1, Es-2, Es-3), acid phosphatase (ACP, E.C. 3.1.3.2, Acp-1), fructose-1,6-diphosphatase (FDP, E.C. 3.1.3.11, $F d p$ ), peptidases (PEP, E.C. 3.4.11, Pep-1), aminoacylase-1 (ACY-1, E.C. 3.5.1.14, Acy-1), adenosine deaminase (ADA, E.C. 3.5.4.4, Ada - kidney), aldolase (ALDO, E.C. 4.1.2.13, Aldo), fumarate hydratase (FH, E.C. 4.2.1.2, $F h$ ), aconitase (ACO, E.C 4.2.1.3, Aco-1, Aco-2), mannose phosphate isomerase (MPI, E.C. 5.3.1.8, Mpi), and glucose phosphate isomerase (GPI, E.C. 5.3.1.9, Gpi-1, Gpi-2).

At the polymorphic loci, the most common allele in the Brakkekuil population was designated arbitrarily "100". Variant alleles were designated according to the relative electrophoretic mobility of the corresponding allozymes. Indices of genetic variation (proportion of polymorphic loci $(P)$, expected $\left(H_{e}\right)$ and observed $\left(H_{o}\right)$ average heterozygosity), Wright's $F$-statistics, genetic distances, and tests for agreement of observed genotypes with Hardy-Weinberg expectations were calculated using the BIOSYS-1 programme package (release 1.7, Swofford and Selander 1989).

\section{Results}

\section{Genetic variation}

Three loci were polymorphic: Pgm-1, Acy-1, and Gpi-1 (Table 1) but Acy-1 was the only one polymorphic in all five populations. Animals from both Willem Pretorius (PRE) and Koppies Dam (KOP - descended mainly from PRE founders) were polymorphic for Pgm-1. Blesbok from Middlekop farm (MID) were the only ones polymorphic for Gpi-1. In none of the populations studied the observed genotypes deviated from Hardy-Weinberg expectations. Allelic frequencies, single locus heterozygosities, average heterozygosity, the proportion of polymorphic loci,

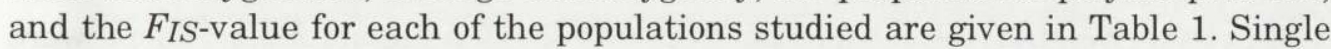
locus and mean values of Wright's $F$-statistics are given in Table 2. The populations separated out by genetic distance into two distinct groups, those from the Cape Province and those from the Orange Free State (Table 3). 
Table 1. Allelic frequencies and indices genetic variation in five blesbok populations. BRA - Brakkekuil, KOP - Kopies Dam, BEN - Benfontein, MID - Middlekop, PRE - Willen Pretorius Game Reserve; sample sizes in parentheses. $h_{e}\left(h_{o}\right)$ - expected (observed) single locus heterozygosity, $H_{e}\left(H_{0}\right)$ - expected (observed) average heterozygosity over 45 loci, $P$ - proportion of polymorphic loci, $F_{I S}$ - inbreeding coefficient. Unbiased expected heterozygosity was calculated according to Nei (1978).

\begin{tabular}{|c|c|c|c|c|c|c|}
\hline Locus & Allele & BRA (27) & KOP (14) & BEN (18) & MID (19) & PRE (23) \\
\hline \multirow[t]{4}{*}{ Pgm-1 } & 100 & 1.0 & 0.964 & 1.0 & 1.0 & 0.935 \\
\hline & 200 & 0.0 & 0.036 & 0.0 & 0.0 & 0.065 \\
\hline & $h_{e}$ & 0.0 & 0.071 & 0.0 & 0.0 & 0.125 \\
\hline & $h_{o}$ & 0.0 & 0.071 & 0.0 & 0.0 & 0.130 \\
\hline \multirow[t]{4}{*}{ Acy-1 } & 100 & 0.574 & 0.929 & 0.417 & 0.868 & 0.326 \\
\hline & 113 & 0.426 & 0.071 & 0.583 & 0.132 & 0.174 \\
\hline & $h_{e}$ & 0.489 & 0.138 & 0.500 & 0.235 & 0.294 \\
\hline & $h_{o}$ & 0.556 & 0.143 & 0.500 & 0.263 & 0.348 \\
\hline \multirow[t]{8}{*}{ Gpi-1 } & -100 & 1.0 & 1.0 & 1.0 & 0.895 & 1.) \\
\hline & -50 & 0.0 & 0.0 & 0.0 & 0.105 & 0)$. \\
\hline & $h_{e}$ & 0.0 & 0.0 & 0.0 & 0.193 & 0)$. \\
\hline & $h_{o}$ & 0.0 & 0.0 & 0.0 & 0.211 & 0)$. \\
\hline & $P$ & 0.022 & 0.044 & 0.022 & 0.044 & 0.144 \\
\hline & $H_{e}$ & 0.011 & 0.005 & 0.011 & 0.010 & 0.309 \\
\hline & $H_{o}$ & 0.012 & 0.005 & 0.011 & 0.011 & 0.011 \\
\hline & $F_{I S}$ & -0.136 & -0.057 & -0.029 & -0.135 & -0.140 \\
\hline
\end{tabular}

Table 2. Summary table of $F$-statistics by locus for the five blesbok populations studied.

\begin{tabular}{lrrr}
\hline Locus & $F_{I S}$ & $F_{I T}$ & $F_{S T}$ \\
\hline Pgm-1 & -0.058 & -0.021 & 0.035 \\
Acy-1 & -0.114 & 0.097 & 0.190 \\
Gpi-1 & -0.118 & -0.022 & 0.086 \\
Mean & -0.109 & 0.077 & 0.168
\end{tabular}

Table 3. Genetic distance between five popuations of blesbok. Below diagonal: modified Rogers distance (Wright 1978), above diagonal: unbiased genetic distance (Nei 1978).

\begin{tabular}{lccccc}
\hline & BRA & KOP & BEN & MID & PRE \\
\hline BRA & - & 0.003 & 0.000 & 0.002 & 0.001 \\
KOP & 0.053 & - & 0.006 & 0.000 & 0.000 \\
BEN & 0.023 & 0.076 & - & 0.005 & 0.004 \\
MID & 0.047 & 0.019 & 0.069 & - & 0.000 \\
PRE & 0.039 & 0.016 & 0.062 & 0.020 & - \\
\hline
\end{tabular}

\section{Body mass variation}

No body weights were collected from the Benfontein animals. There were significant differences in body mass between the other populations (Table 4 ). Sexes differed significantly in weight as did animals of different age groups. No statistical interactions were significant. Animals from Brakkekuil averaged more tha $10 \mathrm{~kg}$ 
Table 4. Mean body weights $(\mathrm{kg})$ for adult blesbok from four sites. Homogeneous groups have the same letter.

\begin{tabular}{lcc}
\hline Site & Weight & Group \\
\hline Brakkekuil & 57.3 & A \\
Middlekop & 68.6 & B \\
Willem Pretorius & 72.2 & BC \\
Koppies Dam & 75.1 & C \\
Male & 71.1 & \\
Female & 65.4 & \\
\hline
\end{tabular}

Table 5. Mean liver trace element concentrations (ppm) of blesbok from five different sites.

\begin{tabular}{lrrrrr}
\hline Site & $\mathrm{Cu}$ & $\mathrm{Fe}$ & $\mathrm{Zn}$ & Mo & Se \\
\hline Brakkekuil & 63 & 295 & 101 & 4.1 & 0.75 \\
Benfontein & 169 & 342 & 99 & 3.3 & 1.50 \\
Middlekop & 115 & 272 & 75 & 3.9 & 0.22 \\
Koppies Dam & 70 & 313 & 80 & 2.9 & 0.25 \\
Willem Pretorius & 121 & 387 & 77 & 2.3 & 0.20 \\
\hline
\end{tabular}

less than those from other populations. Adult animals from Brakkekuil had significantly different body weights between years.

\section{Trace element levels}

Trace elements varied considerably between the populations (Table 5). Manganese did not differ significantly between populations. Females had somewhat lower copper and higher zinc levels than males. There were no differences between age classes. Brakkekuil animals had significantly lower copper concentrations and higher molybdenium concentrations than those from other populations.

A principal components analysis of trace element levels reveals that the major contrast is between animals relatively low in copper and high in molybdenium (Fig. 1). The Brakkekuil animals fall in the first group while the other populations fall in the latter. A regression of the first principal component with body weight produces a significant correlation $\left(R^{2}=0.36, p=0.003\right)$. Animals low in copper and high in molybdenium are lighter. The regression is not altogether convincing because the majority of the lighter animals come from Brakkekuil. When the data

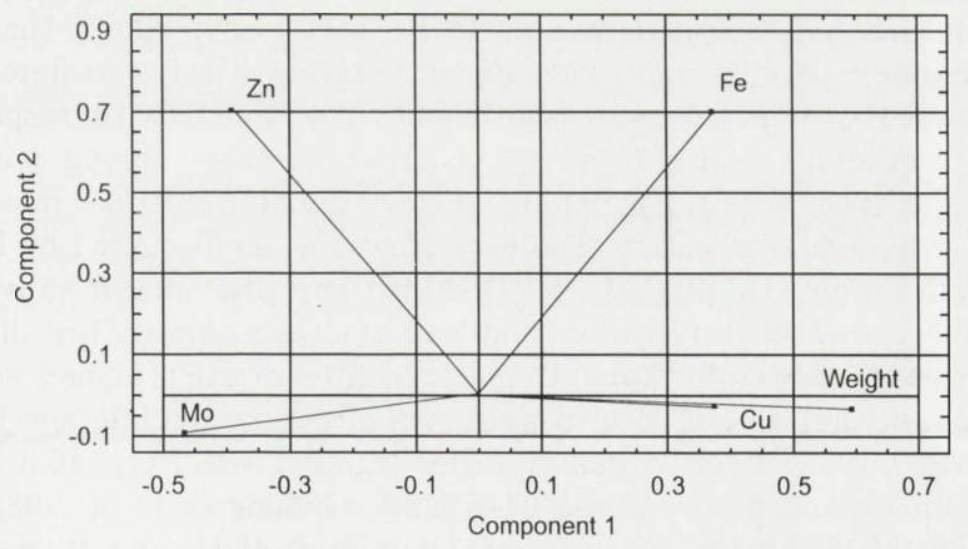

Fig. 1. Plot of first two principal components of the trace element concentrations of blesbok livers. 
is partitioned by farm then a significant relationship remains for Koppies Dam and Middlekop only.

\section{Discussion}

The aim of the present study was to test the hypotheses that blesbok from Brakkekuil are genetically depleted due to small effective population size, and that small body size and abnormalities in body colouration are a result of inbreeding depression rather than of environmental influences (cf Bigalke and van Hensbergen 1992).

The data obtained in the present study, including also considerably larger populations, show that $H$ - and $P$-values in all of them are as low or nearly as those in Brakkekuil blesbok. In order to explain this result it may be hypothesised that, in spite of partially quite high actual population sizes, all of the populations studied had experienced one or more bottlenecks during their history. Apart from the Middlekop population (MID) with unknown history and from the Willem Pretorius Game Reserve (PRE), small numbers of founder individuals or considerable fluctuations of population sizes have been indeed recorded (see Study area). In Koppies Dam (KOP) the effect of a small number of founders is to some extent compensated by later massive introductions from PRE, which are indicated by the exclusive presence of the Pgm-1 polymorphism in PRE and KOP. As expected from population histories, $P$-values in Brakkekuil (BRA) and in Benfontein (BEN) with $2.2 \%$ are lower than in MID, PRE, and KOP with $4.4 \%$. Nevertheless, compared with a mean $P$ of $13.2 \%$ and a mean $H$ of $3.4 \%$ over 14 ungulate species without known bottlenecks in population size (Hartl and Pucek 1994), the figures of $P$ and $H$ also for the large blesbok populations (Table 1 ) are extremely low. Thus, if low genetic variation in this species is due to population bottlenecks, earlier ones than those reported for the populations studied must be assumed.

Alternatively, low genetic variation in blesbok may be attributed to their polygynic mating system. Apollonio and Hartl (1993) have shown that levels of genetic variation in cervids and bovids appear to be negatively correlated with the degree of polygyny. The opposite relationship was found with respect to the inbreeding coefficient and the extent of differentiation among populations. Contrary to the hypothesis of Apollonio and Hartl (1993) $F_{I S}$-values in our blesbok populations are slightly negative (Table 1). However, as discussed by Kurt et al. (1993), a high annual culling rate may disturb any pronounced substructuring caused by a territorial mating system and lead to a reshuffling of breeding parties in the next season. Absolute (Table 3) genetic differentiation among populations is comparable to that among local populations of other ungulate species (see eg Hartl et al. 1990, 1993). Relative genetic differentiation with $F_{S T}=16.8 \%$ is almost as high as among subspecies of red deer (22\%, Gyllensten et al. 1983). But as stated by Nei (1975), in the case of very low values of $H_{e}$ and $H_{0}$ estimates of $F_{S T}\left(=G_{S T}\right)$ may be large even if the absolute genic differentiation is small. 
Given the scarce electrophoretic data available on genetic variability in larger populations of antelopes (cf Bigalke et al. 1993, Grobler and van der Bank 1993) any historical, phylogenetic or sociobiological reasons for low genetic variability in blesbok remain to be investigated in further comparative studies. At any rate, if genetic bottlenecks in the blesbok occurred already a long time ago and/or if a certain rate of inbreeding is typical for its mating system, the present populations should be 'preadapted' to genetic depletion and inbreeding depression is not expected to be a major source of threat (cf Hartl et al. 1986).

As an alternative hypothesis to genetic impoverishment, Bigalke and van Hensbergen (1992) suggested that the small size of the Brakkekuil blesbok may have been due to mineral deficiencies. In fact Brakkekuil blesbok can now be seen to be deficient by comparison with other groups of blesbok only for copper. The difference in weight from year to year suggests that resources in general may be limiting size in this population which is kept at a very high density.

Acknowledgements: Part of this study has been carried out at the Forschungsinstitut für Wildtierkunde und Ökologie der Veterinärmedizinischen Universität Wien. The excellent technical assistance of Anita Haiden is gratefully acknowledged.

\section{References}

Apollonio M. and Hartl G. B. 1993. Are biochemical-genetic variation and mating systems related in large mammals? [In: Ecological genetics in mammals. G. B. Hartl and J. Markowski, eds]. Acta Theriologica 38, Suppl. 2: 175-185.

Bigalke R. C. 1950. Wildlife conservation in the Union of South Africa. Fauna \& Flora 1: 5-9.

Bigalke R. C. and van Hensbergen H. J. 1992. Observations on a reproductively isolated population of blesbok (Damaliscus dorcas phillipsi) in an mineral deficient environment. [In: Ongulés/Ungulates 91. F. Spitz, G. Janeau, G. Gonzalez and S. Aulagnier, eds]. S.F.E.P.M. - I.R.G.M., Paris, Toulouse: $497-503$.

Bigalke R. C., Hartl G. B., Berry M. P. S. and van Hensbergen H. J. 1993. Population genetics of the springbok Antidorcas marsupialis - a preliminary study. [In: Ecological genetics in mammals. G. B. Hartl and J. Markowski, eds]. Acta Theriologica 38, Suppl. 2: 103-111.

Grillitsch M., Hartl G. B., Suchentrunk F. and Willing R. 1992. Allozyme evolution and the molecular clock in the Lagomorpha. Acta Theriologica 37: 1-13.

Grobler J. P. and van der Bank F. H. 1993. Genetic diversity and differentiation of the three extant southern African species of the subfamily Hippotraginae (Family: Bovidae). Biochemical Systematics and Ecology 21: 591-596.

Gyllensten U., Ryman N., Reuterwall C. and Dratch P. 1983. Genetic differentiation in four European subspecies of red deer. (Cervus elaphus L.). Heredity 51: 561-580.

Hartl G. B. and Höger H. 1986. Biochemical variation in purebred and crossbred strains of domestic rabbits (Oryctolagus cuniculus L.). Genetical Research, Cambridge 48: 27-34.

Hartl G. B., Markov G., Rubin A., Findo S., Lang G. and Willing R. 1993. Allozyme diversity within and among populations of three ungulate species (Cervus elaphus, Capreolus capreolus, Sus scrofa) of Southeastern and Central Europe. Zeitschrif für Säugetierkunde 58: 352-361.

Hartl G. B. and Pucek Z. 1994. Genetic depletion in the European bison (Bison bonasus) and the significance of electrophoretic heterozygosity for conservation. Conservation Biology 8: 167-174.

Hartl G. B., Schleger A. and Slowak M. 1986. Genetic variability in fallow deer, Dama dama L. Animal Genetics 17: 335-341. 
Hartl G. B., Willing R., Lang G., Klein F. and Köller J. 1990. Genetic variability and differentiation in red deer (Cervus elaphus L.) of Central Europe. Genetics, Selection, Evolution 22: 289-306.

Kurt F., Hartl G. B. and Völk F. 1993. Breeding strategies and genetic variation in European roe deer Capreolus capreolus populations. [In: Ecological genetics in mammals. G. B. Hartl and J. Markowski, eds]. Acta Theriologica 38, Suppl. 2: 187-194.

Nei M. 1975. Molecular population genetics and evolution. North-Holland, Amsterdam: 1-288.

Nei M. 1978. Estimation of average heterozygosity and genetic distance from a small number of individuals. Genetics 89: 583-590.

Smithers R. H. N. 1983. The mammals of the southern African subregion. University of Pretoria, Pretoria: $1-736$.

Swofford D. L. and Selander R. B. 1989. BIOSYS-1. A computer program for the analysis of allelic variation in population genetics and biochemical systematics. Release 1.7. User's manual. Illinois Natural History Survey, Champaign.

Wright S. 1978 Evolution and the genetics of populations. Vol. 4. Variability within and among natural populations. University of Chicago Press, Chicago: 1-580.

Received 23 March 1995, accepted 1 September 1995. 